\title{
Editorial
}

\section{Future possibilities for The International Journal of Risk and Safety in Medicine}

"The International Journal of Risk and Safety in Medicine (JRS) is concerned with rendering the practice of medicine as safe as it can be; that involves promoting the highest possible quality of care, but also examining how those risks which are inevitable can be contained and managed". That is our vision as stated in JRS but it is, more specifically, aiming to examine both harms and benefits of medical care outcomes in general, though with some emphasis on medicines, thereby allowing both health professionals and patients to better assess what is the best treatment in a given situation. Prof. Graham Dukes, the founder of JRS, also included the legal profession's views since legal practitioners are very much involved over risk and benefit in health care, and now it seems wise to include any other views so long as they are relevant, well argued, and with some worthwhile evidence.

Currently, there are only a handful of submissions within the above scope. Many of the submissions are repeating others' work in their own medical environments. They neither contain new research methods, nor do they add anything new in the way of viewpoints or results. In essence the journal is in danger of being used as a place for me-too work that probably has national/regional significance but offers no originality in an international context.

We do see that it is of value to bring on new writers, but we also think that JRS might do more to promote the main aim of its unusual theme of describing the phenomenology of benefits and harms experienced by people in as full a way as possible and then taking that knowledge to give a picture of why medicines can be both effective and risky, depending upon the particular dispositions of the individual (and the particular medicine) as well as the context in which the medicine was used.

We will start by asking our current board members for ideas, and since we are looking for new board members, we are sure they would like to be involved in the discussions too, and also others who perhaps help us by being peer reviewers. One ongoing issue is the limited availability of both active editors and, of course reviewers, a situation that both frustrates the smooth and timely operation of the editorial process and does little to encourage really interesting papers.

So, we have some suggestions for changes and again welcome comments from any source particularly focusing on the issues of risk and benefit. We might not be able to implement all ideas at once, but all suggestions will be valued.

(1) As mentioned above, we are making a request for those interested in the phenomenology affecting the success or failure of therapies with the aim of trying to improve individual clinical outcomes. Please let us know if you wish to be involved with us in this area and submit a short summary of the reasons for your interest and a short summary of any relevant personal background.

(2) This complex topic lends itself to a way of assessing submissions to the journal that could include the publication of part of the reviewers', or editors', comments. This would be subject to the reviewers' agreements and managing confidentiality matters. Since anyone who has to make decisions, when 
there are a number of choices possible with differing outcomes knows, it can be a very complex task in which many choices (short- and long-term: direct and indirect effects) need to be considered, each with their different reasoning. The publication of the reviewer's ideas on the proposals and strength of the work in any paper may start an exciting discussion on the topic. In turn this might attract good reviewers and editors since their contribution could also be a publication for them. The idea is not entirely new and any basic criticism of any obvious errors in the submitted paper would not be part of any such publication but managed separately using the confidential 'comments to editor section' in the Editorial Manager peer review platform, which would be a slight shift of use for that section.

(3) I (IRE) have thought for a long time about the large amount of more or less voluntary or low paid consulting work that goes into publications, particularly web publications. I hear over and again people saying that publishers make large amounts of money whilst those producing and assessing the submissions get little or nothing for all their efforts. My answer always is, 'Journals must have enough income to keep going for all you people who need the service to get you known in the medical scientific area, and to have your work reviewed. We have had great service from journals and learned a great deal in the process which is a nearly free service to enable us all to become respected professionals: that is a debt you and we owe the publishers of journals. In addition, someone took their time and trouble to review your paper. Now it's your turn to be doing the reviewing and you must take this responsibility seriously, do a good and timely service, and don't turn requests down unless it is absolutely necessary'. What people often forget is that there are a lot of factors involved in publishing a paper, including other services that need to be paid for (peer review platform and typesetting costs, for example).

(4) We have an increasing feeling that universities globally have been guilty of making the number of professional/scientific publications the major yardstick by which professional promotions are decided, and medical publishers have been willing to assist by introducing ever more journals. The overall effect of this development over time is that there are many more papers submitted for publication that may be technically OK but are not particularly interesting and do little to add any useful knowledge. We also know that there is an increasing amount of outright plagiarism and even fraudulent work that requires alert editors and reviewers, to counteract such activity.

In summary we will find ways to promote JRS out of the traditional ways of operating into more active and even experimental modes, attracting interesting submissions and committed editors and reviewers. There's certainly much more to consider: from special JRS editions through to the use of podcasts and the use of the web in general, perhaps for online debate and thought experiments. Please let us share your ideas, and we'll help to have the best ones out there.

I. Ralph Edwards and Marie Lindquist Editors-in-Chief 